\title{
Correction to: Steering System Models - An Efficient Approach for Parameter Identification and Steering System Optimization
}

J. Lin, T. Kloos, P. E. Pfeffer

Correction to:

Chapter 36 in: J. Lin, T. Kloos, P. E. Pfeffer, Steering System Models - An

Efficient Approach for Parameter Identification and Steering System

Optimization

DOI 10.1007/978-3-658-18459-9_36

The author J. Lin was missed in this chapter and it has been corrected.

The updated online version of the original chapter can be found at DOI 10.1007/978-3-658-18459-9_36. 